\title{
Haglund Syndrome - A Case of Bilateral Involvement
}

\author{
Marcio Luis Duarte ${ }^{1,2 *}$, Andre de Queiroz Pereira da Silva ${ }^{1}$, Jose Luiz Masson de Almeida Prado ${ }^{1}$ and Marcelo de \\ Queiroz Pereira da Silva ${ }^{1}$
}

${ }^{1}$ Radiologist, WEBIMAGEM, Brazil

${ }^{2}$ Masterdegree in Evidence-Based Health at UNIFESP, Brazil

*Corresponding author: Marcio Luis Duarte, WEBIMAGEM, Avenida Marques de Sao Vicente 446, Sao Paulo, Brazil

\begin{abstract}
Haglund syndrome is a cause of posterior heel pain and occurs commonly in adolescent girls who wear high heels with restrictive heel counters and may occur in people with rheumatoid arthritis. Is characterized clinically by thickening of the soft tissues at the Achilles tendon insertion or a painful "pump bump" and retrocalcaneal bursitis, Achilles tendinitis, and a prominent posterosuperior calcaneal border or bursal projection. We report a case of a 59 years-old woman with bilateral Haglund syndrome which did not needed surgical treatment, being the conservative treatment enough to improve the patient's quality of life.
\end{abstract}

Keywords: Calcaneus; Magnetic resonance imaging; Foot diseases

\section{Introduction}

Haglund syndrome is a cause of posterior heel pain and was first described by Patrick Haglund, in 1928, to occur in patients who had a prominence of the posterosuperior surface of the calcaneus [1]. It occurs commonly in adolescent girls who wear high heels with restrictive heel counters and may occur in people with rheumatoid arthritis [1]. Haglund syndrome has also been termed "pump bump," "winter heel," "knobby heels," "calcaneal altus," "highbrow heels," and "cucumber heels" [1]. Haglund syndrome is characterized clinically by thickening of the soft tissues at the Achilles tendon insertion or a painful "pump bump" and retrocalcaneal bursitis, Achilles tendinitis, and a prominent posterosuperior calcaneal border or bursal projection [1-4].
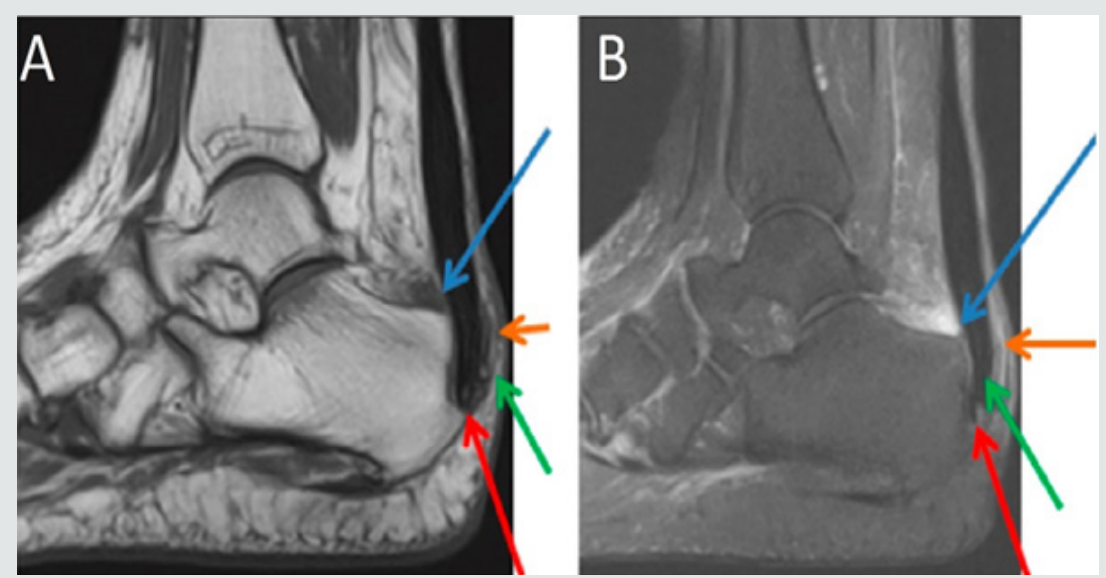

Figure 1: Sagittal section MRI in T1 sequence in A and T2 STIR sequence in B of the right ankle demonstrating posterior calcaneal spur (red arrow), liquid in retrocalcaneal bursa (blue arrow), liquid in subcutaneous calcaneous bursa (orange arrow), and calcaneal tendinopathy (green arrow). 

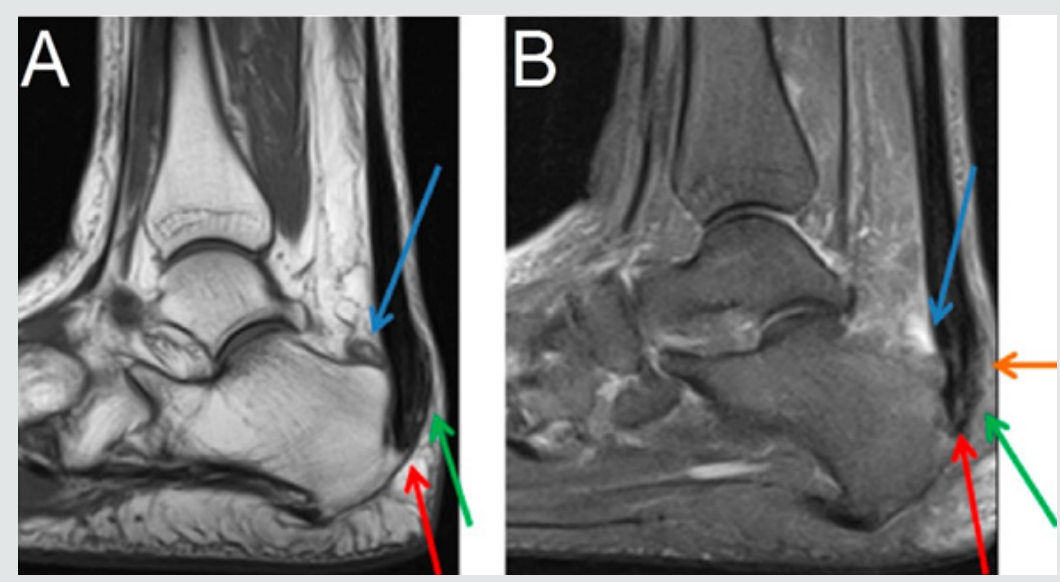

Figure 2: Sagittal section MRI in T1 sequence in A and T2 STIR sequence in B of the left ankle demonstrating posterior calcaneal spur (red arrow), liquid in retrocalcaneal bursa (blue arrow), liquid in subcutaneous calcaneous bursa (orange arrow), and calcaneal tendinopathy (green arrow).

\section{Case Presentation}

59 years-old woman with pain and swelling in both feet for four months that get worse when use slippers and when she wake up and put her feet in the floor for the first time in the day. The patient denies other complaints and surgeries. At physical examination refers pain at the palpation of in the posterior and inferior regions of the ankle. The Magnetic Resonance Imaging (MRI) demonstrates posterior and plantar calcaneal spurs, liquid in retrocalcaneal and subcutaneous calcaneous bursa, and calcaneal tendon with heterogeneous signal and thickened $(1.4 \mathrm{~cm}$ at left and $1.2 \mathrm{~cm}$ at right), markedly in their insertion with adjacent bone edema (Figures $1 \& 2$ ). The set of findings are compatible with Haglund syndrome. The patient started conservative treatment with non-steroidal anti-inflammatories, change of footwear and physiotherapy, presenting a good response, not requiring surgery.

\section{Discussion}

Haglund syndrome is caused by mechanically induced inflammation of the Achilles tendon and its bursa, from abnormally high pressure between the bursal projection of the calcaneus, the Achilles tendon, and the bursa [1,5]. Patients with bursitis have erythema and swelling over the bursa and tenderness to direct palpation [2] besides pain with dorsiflexion of the foot [6]. Clinically, by physical examination alone, it may be difficult to distinguish Haglund's syndrome from other causes of hindfoot pain such as Reiter's disease, rheumatoid arthritis, or isolated local conditions such as superficial tendon Achilles bursitis secondary to poor shoe fit [7]. Plain radiograph in a lateral standing position is useful to assess the presence of a prominent bursal projection of the calcaneum, the Haglund deformity [3]. Loss of a lucent retrocalcaneal recess is an important indication of underlying retrocalcaneal bursitis [3]. The Achilles tendon is swollen, and dystrophic calcifications may also be seen [3].

MRI may be required for ambiguous or clinically equivocal cases [3]. The cardinal soft tissue abnormalities, namely Achilles tendinopathy, and retrocalcaneal and retroachilles bursitis are more easily and directly depicted by MRI [3]. The detection of marrow oedema within the prominent bursal projection is likely to support the repetitive mechanical compression and inflammation as the pathological mechanism in this condition [3]. Treatment of Haglund deformity, with or without bursitis, targets decreasing the pressure and inflammation with openheeled shoes, anti-inflammatory or analgesic medications, and corticosteroid injections [2]. Physical therapy may also help reduce pain. In recalcitrant cases, surgery to remove the Haglund deformity may be necessary [2].

The nonsurgical treatment, combined with modifications in daily shoe wear, is an appropriate initial treatment for pain relief of Haglund's syndrome [7]. Using ultrasound guidance to inject the retrocalcaneal bursa is a simple, reliable method of ensuring accurate delivery of medication into the bursa and avoiding intratendinous injection [7].

\section{References}

1. Lu CC, Cheng YM, Fu YC, Tien YC, Chen SK (2007) Angle analysis of Haglund syndrome and its relationship with osseous variations and Achilles tendon calcification. Foot Ankle Int 28(2): 181-185.

2. Tu P, Bytomski JR (2011) Diagnosis of heel pain. Am Fam Physician 84(8): 909-916.

3. Kucuksen S, Karahan AY, Erol K Haglund (2012) syndrome with pump bump. Med Arch 66(6): 425-427.

4. Ahn JH, Ahn CY, Byun CH, Kim YC (2015) Operative Treatment of Haglund Syndrome with Central Achilles Tendon-Splitting Approach. J Foot Ankle Surg 54(6): 1053-1056.

5. Jiménez Martín F, Alonso Valdazo MD, Díaz Peña G, Fernández Leroy J, Hernández Herrero D (2016) Haglund's syndrome. Two case reports. Reumatol Clin.

6. Sierra Solís A, Romero López AI, Martín-Rodrigo JL (2012) Síndrome de Haglund. Semergen 38(1): 64-66

7. Sofka CM, Adler RS, Positano R, Pavlov H, Luchs JS (2006) Haglund's syndrome: diagnosis and treatment using sonography. HSS J 2(1): 27-29. 
This work is licensed under Creative Commons Attribution 4.0 License

To Submit Your Article Click Here:

Submit Article

DOI: $10.32474 /$ OSMOAJ.2019.03.000155

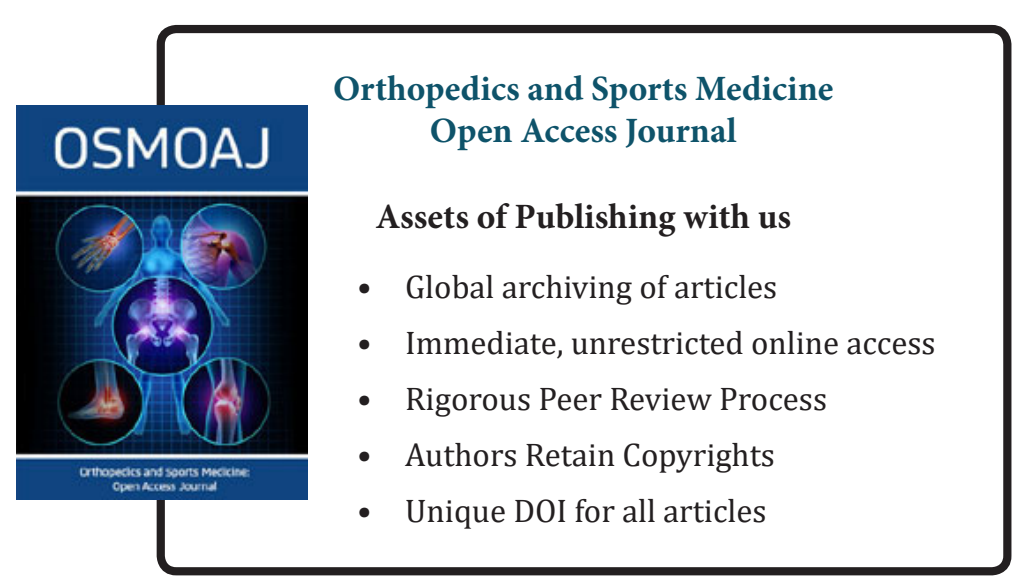

